\title{
Variations in Children's Affective Subjective Well-Being at Seven Years Old: an Analysis of Current and Historical Factors
}

\author{
Gwyther Rees ${ }^{1}$
}

Accepted: 14 December 2017 / Published online: 2 February 2018

(C) The Author(s) 2018. This article is an open access publication

\begin{abstract}
There is a growing amount of evidence on children's subjective wellbeing in general, but research on this topic with younger children is still scarce. In the UK, Wave 4 of the Millennium Cohort Study asked questions about positive and negative affect to a nationally representative sample of over 13,000 children aged around seven years old. The study also contains other information reported by children about their friendships, family relationships, experiences of school and of being bullied; and extensive data gathered from parents across four survey waves starting when the child was nine months old. This paper analyses the extent to which variations in children's positive and negative affect (happiness and sadness) at the age of seven years old are associated with contemporaneous factors reported by children (e.g. bullying) and parents (e.g. household income, parent-child relationships). It also analyses the extent to which socio-economic and family factors earlier in childhood can predict children's affective subjective well-being at seven years old. A comparison is made between findings for affective subjective wellbeing and for emotional and behavioural difficulties. The analysis identifies important differences in factors associated with variations in positive affect, negative affect and emotional and behavioural difficulties. The paper considers the implications of these findings for future research and also in terms of the potential to improve children's experience of childhood.
\end{abstract}

Keywords Subjective well-being $\cdot$ Positive affect $\cdot$ Negative affect $\cdot$ Middle childhood

Gwyther Rees

ReesGN@cardiff.ac.uk

1 WISERD, School of Social Sciences, Cardiff University, Second Floor, 1-3 Museum Place,

Cardiff CF10 3BD, UK 


\section{Introduction}

A great deal of progress has been made in recent years in exploring the subjective wellbeing (SWB) of children from around the age of around 10 or 11 years old upwards. Overall levels of SWB and variations according to age, gender and other factors have been measured; and substantial evidence has accumulated about correlates of SWB, primarily based on cross-sectional studies. Some recent studies have also begun to undertake longitudinal analysis of SWB and factors associated with it. However, the SWB of children younger than ten years of age is much less well-explored. An exception to this is the international Children's Worlds survey which gathered selfreport information from children aged around eight, ten and 12 years old (Rees and Main 2015; Rees et al. 2016). Data from this survey is analysed in a number of other articles in the special issue. Children's Worlds is a valuable new source of information on the SWB of children in this age range, but it has the limitation of only gathering data from children themselves. This means that it is not possible to explore variations in SWB according to factors that children are unable to report on - such as household income - or to incorporate the perspectives of parents. This article addresses these issues by making use of a large-scale birth cohort study in the UK which gathered selfreport data, including some questions about SWB, from children at around the age of seven years old. This data can be linked with extensive other information on children's lives reported by parents. As well as covering an under-researched age group, it also contributes to the limited amount of longitudinal evidence on the extent of links between early childhood circumstances and children's later SWB.

\subsection{Conceptualising the SWB of Younger Children}

In extending research on SWB to include younger age groups of children it is necessary to carefully consider conceptual issues. Current concepts of SWB commonly used in research with older children have been derived from ideas originally developed through researching adult populations. A very common framework for thinking about adults' SWB is the tripartite model (Andrews and Withey 1976; Diener 1984). This model proposes a division between cognitive and affective components. The cognitive component consists of people's evaluations of their lives as a whole (life satisfaction) and specific aspects of their lives (domain satisfactions). Many studies of older children also explicitly or implicitly use the tripartite framework; although the primary focus has been on cognitive SWB. Generally, these concepts seem to have worked reasonably well in studies of children from around the age of ten years old upwards (e.g. Huebner and Dew 1996). So far there is less evidence of how well SWB measures based on these ideas work with children below ten years old. One question to be addressed is what is the typical lower age limit below which children are unable to report reliably on their SWB. A lower age limit is inevitable as it is not possible to imagine that a child of one day old can make a cognitive evaluation of their life as a whole! It may be that practical lower age limits vary for different components of SWB. In particular it seems plausible that children may be able to conceptualise and report on their moods and emotions at a younger age than they are able to make cognitive evaluations of life satisfaction. However, at this stage this is only a hypothesis and much work needs to be done to test different questions and measures with younger children of different ages. 


\subsection{Factors Associated with Variations in SWB}

Most of the current research evidence on factors associated with SWB is based on cross-sectional analysis. I will focus here on research in the UK as this is directly relevant to the data set being analysed for this paper and there is some evidence that the correlates of SWB vary in important ways from one country to another (Rees 2017). Factors such as age, gender, material deprivation (Main and Bradshaw 2012), personality (Goswami 2014), family structure/living situation (Rees et al. 2010), quality of family relationships (Rees and Bradshaw 2016), peer relationships (Goswami 2012) and bullying (Rees and Bradshaw 2016), school experiences (Patalay and Fitzsimons 2016), characteristics of the local area (Rees and Bradshaw 2016), and children's daily activities (Abdallah et al. 2014) have all been found to be linked with variations in children's SWB. Although the impact of these factors on children's SWB is often assumed or implied in this literature, in fact little is know about directions of influence. Children's SWB is highly unlikely to cause variations in some factors such as family economic circumstances. However for many of the other factors that have been the subject of research, the situation is a lot less clear. For example, there is strong evidence in the UK and some other countries of associations between children's experiences of being bullied and their SWB. This may be because being bullied leads to lower SWB; but is also plausible that children who have low SWB may be more vulnerable to being bullied, or that some other factor such as poverty explains the relationship.

There are some UK studies that have begun to look at connections between children's SWB and other factors longitudinally. In a rare piece of research with children below the age of ten years old, Parkes et al. (2016) highlighted the importance of parent-child relationships in middle childhood in predicting children's level of SWB around two years later (between the ages of seven and eight). Their analysis also suggests that parenting also mediates the effect of early socio-economic factors on children's later SWB. Other UK longitudinal studies focus on the SWB of children aged 10 years old and over. Robson (2010) found that changes in family structure adversely affected children's life satisfaction. Powdthavee and Vernoit (2013) similarly found some evidence of longitudinal links between parental unemployment and children's life satisfaction, although this varied by age and gender. Rees (2017) reported that a range of family and socio-economic factors in early and middle childhood had very little association with children's SWB at the age of 11 years old. There is a need for more research that explores such longitudinal associations throughout childhood and adolescence.

\subsection{The Distinction Between Children's Subjective Well-Being and Other Indicators of their Well-Being}

Another theme that has begun to be explored in the UK relates to the similarities and differences between SWB and other indicators of children's well-being. There is considerable research evidence in the UK that family and socio-economic factors can explain variations and inequalities in a range of child 'outcomes' such as cognitive development, emotional and behavioural development, educational attainment and health indicators. For example, Dickerson and Popli (2015) found a substantial socioeconomic gradient in children's cognitive development at the age of seven. The 
similarity and differences between SWB and emotional and behavioural difficulties (EBD) is particularly pertinent because indicators of EBD have sometimes been proposed as a proxy indicator for children's SWB. It is not clear whether this idea is justified. In adult populations there is both overlap and difference between indicators of mental health problems and people's life satisfaction or happiness (Bergsma et al. 2011). Two recent UK studies (Patalay and Fitzsimons 2016; Rees 2017) have compared the predictive power of various factors in children's lives on indicators of their SWB and EBD at the age of 11 years old, and have found substantial differences. This is an area that warrants further exploration as such differences provide insights into the value of different approaches to measuring children's well-being (in a broad sense).

\subsection{Research Questions}

The current article will address the following questions:

1. To what extent is children's SWB at the age of seven years old associated with other factors in their lives that have been identified as relevant to older children's SWB?

2. To what extent is children's SWB at the age of seven years old predicted by family and socioeconomic factors in early childhood?

3. To what extent do the findings on the first two questions differ when using an indicator of emotional and behavioural difficulties as the dependent variable?

In answering these questions, the analysis will make a contribution to research on children's SWB in several ways. First, it will contribute to the limited evidence (in the UK and globally) on the SWB of children under the age of ten years old. Second, it will add to the small amount of evidence on SWB utilising longitudinal analysis. Third, it will shed further light on the similarities and differences between measures of SWB and other measures of children's well-being.

\section{Method}

\subsection{Data Source}

The data used in this paper is taken from the Millennium Cohort Study - a birth cohort study of a large and representative sample of children in the UK born near the start of the new millennium. This study began with 18,522 children in the first sweep when children were nine months old, some additional children who had been missed from the first sweep were introduced to the study in the second sweep at around the age of three years old. Four subsequent sweeps have so far been undertaken when children are around five, seven, 11 and 14 years old respectively. The data analysed here is from the first and fourth sweeps. The main focus is on the fourth sweep, conducted when children were around seven years old. At this point, 13,857 children were still actively involved in the study of which 13,244 completed a questionnaire which included some SWB questions which are discussed more fully below. The analysis covers all of these children with the exclusion of second- and third-born children in twin and triplet groups that are excluded to avoid issues of clustering of children within the same household. 
This leaves a total of 13,066 children available for analysis. The data used is from a short child self-report questionnaire and from extensive information provided by the main parent (usually the mother). Additionally, some information on children's family and socioeconomic circumstances when they were nine months old, provided at that time by the parent, is also included. The intention is to test the extent to which very early childhood circumstances predict children's later SWB. The method used here could in future also be extended to incorporate additional information gathered in the second and third sweeps. Because some children only joined the survey at the second sweep, the analysis including information when children were nine months old can only include 12,602 out of the 13,066 children included in the fourth sweep analysis.

\subsection{Measures}

\subsubsection{Dependent Variables: Affective Subjective Well-Being}

The child self-completion questionnaire includes seven questions that might be deemed to relate to the affective component of SWB (there were no questions which appeared to tap into the cognitive component). These all took a similar format and asked children about the frequency with which they felt particular things using a three-point response scale - 'All of the time', 'Some of the time' and 'Never'. The questions asked about feeling happy, getting worried, feeling sad, being quiet, liking to be alone, laughing and losing one's temper. Initially, the intention was to create multi-item measures of positive and negative affect from these items. The first version of this paper attempted to do this by combining the items on happiness and laughing to represent positive affect and the items on sadness and worrying to represent negative affect. However both reviewers of the paper raised queries about this approach, including whether a question about frequency of laughing can be regarded as representing positive affect. The reviewers' concerns seemed warranted and so, the analysis presented in this paper is based entirely on the questions about feelings of happiness and sadness. There are conceptual grounds for considering these to be good single-item measures of positive and negative affect respectively. Barrett and Russell (1998) present a circumplex model of affective SWB which has two orthogonal dimensions - unpleasant to pleasant and deactivation to activation. They propose a range of descriptors which represent different points in this two-dimensional space. For example, 'lethargic' is positioned in the quadrant of unpleasant deactivation. In this model, 'happy' and 'sad' are words on the unpleasant to pleasant continuum which are close to the middle and neutral point of the deactivation to activation continuum. Additionally, in everyday language, 'happy' and 'sad' seem to be reasonable representations of positive and negative affect and questions based on these words have been used in this way in other published analysis (Rees and Bradshaw 2016).

In the fourth sweep of the MCS, $36.5 \%$ of children said that they felt happy all of the time; $61.4 \%$ some of the time and $2.1 \%$ never; $3.2 \%$ of children said that they felt sad all of the time, $68.6 \%$ some of the time and $28.2 \%$ never. Due to the wordings and the small number of response options it is clearly not possible to treat these variables as being on a scale. Additionally the responses are highly skewed. As a result it was decided to collapse the two variables into a binary format. For the happiness variable the 'some of the time' and 'never' categories were combined; while for the sadness variable the 'all of the time' and 'some of the time' categories were combined. These 
will be referred to as high and low happiness and high and low sadness respectively. Table 1a shows a cross-tabulation of these two variables for cases included in the final analysis. It provides an illustration of the potential value of measuring positive and negative affect separately. For example, $21 \%$ of the sample were sometimes or always sad but also were happy all of the time.

\subsubsection{Dependent Variable: Emotional and Behaviour Difficulties}

The measure of EBD used is the total difficulties score from the parent-reported Strengths and Difficulties Questionnaire (SDQ) (Goodman 1997). This is a very widely validated and used measure which is also often referred to as a measure of children's mental health problems (e.g. Goodman and Goodman 2012) although the term EBD is used here. The score is calculated from 20 mainly behavioural questions in four sets covering children's emotional symptoms, peer problems, conduct problems and hyperactivity/inattention difficulties. The score ranges from zero to 40 where a higher number indicates greater difficulties. The total difficulties score is highly skewed towards the lower end of the scale (fewer EBD). As the intention of using this variable was to make comparisons with the affective SWB variables it was decided also to create a binary variable for EBD. Various recommended threshold exist for creating SDQ categorical scores. For example, Goodman et al. (1998) report a categorisation of zero to 15 as 'normal', 16 to 19 as 'borderline', and 20 to 40 as 'abnormal' with a community sample of children aged 11 to 16 years old in the UK. However, with children aged seven years old in the MCS the scores tended to be much lower than this, and so it was decided to focus mainly on a cut-off point that included more than $20 \%$ of children in the high EBD category, which was a total difficulties score of more than ten. This is the

Table 1 Cross-tabulation of high and low happiness and sadness (\% of total)

\begin{tabular}{llll}
\hline Table 1a & & & \\
& Low sadness & High sadness & All \\
Low happiness & $12.7 \%$ & $51.1 \%$ & $63.8 \%$ \\
High happiness & $15.4 \%$ & $20.8 \%$ & $36.2 \%$ \\
All & $28.2 \%$ & $71.8 \%$ & $100.0 \%$ \\
Table 1b & & & All \\
& & & $63.8 \%$ \\
Low happiness & Low SDQ & High SDQ & $36.2 \%$ \\
High happiness & $47.6 \%$ & $16.2 \%$ & $100.0 \%$ \\
All & $27.8 \%$ & $8.4 \%$ & $24.6 \%$ \\
Table 1c & $75.4 \%$ & & All \\
Low sadness & & High SDQ & $28.2 \%$ \\
High sadness & & $7.7 \%$ & $71.8 \%$ \\
All & & $16.9 \%$ & $100.0 \%$ \\
\hline
\end{tabular}


binary variable used for the analysis reported in this paper, but several other thresholds were calculated and this did not substantively affect the broad results of the analysis.

Tables $1 \mathrm{~b}$ and $\mathrm{c}$ show cross-tabulations of this binary EBD variable with those for happiness and sadness respectively. These indicate that, while there is clearly an association between the variables, there is also divergence. It is quite possible, for example, for a child to report high levels of sadness but still have a relatively low SDQ score. With binary variables these results are not very conclusive but they are in line with those from other research with adults (e.g. Bergsma et al. 2011) and also with children in the fifth sweep of the MCS (Patalay and Fitzsimons 2016).

\subsubsection{Independent Variables: Family and Socioeconomic, Seven Years Old}

The MCS contains a huge amount of data (the parent-report data file in Wave 4 contains over 10,000 variables). The focus here is on a small set of factors which have been commonly used by other researchers utilising the MCS to explore family and socioeconomic variations in child well-being and outcomes (e.g. Kiernan and Mensah 2009; Sabates and Dex 2015; Flouri et al. 2016). These were: family structure, household income (OECD equivalised), housing tenure, parental employment and number of children in the household. Some commonly-used indicators of parental well-being, such as parental depression, were not included because it is not entirely clear that these are independent of child SWB (there may be a shared genetic component influencing both) and also it is plausible that there is influence in both directions (i.e. children's SWB could affect parent's sense of well-being).

\subsubsection{Independent Variables: Parent-Reported, Seven Years Old}

There are a range of potential variables relating to parent's perceptions and evaluations included in the MCS data set. One set of questions that is relevant to children's SWB, based on the research findings reviewed earlier about the importance of parent-child relationships for children's SWB, focuses on the main parent's view of their relationship with the child. Four question on this topic are utilised in the analysis, asking feelings of closeness to the child, enjoying spending time with the child, expressing affection towards the child, and feeling irritated by the child.

\subsubsection{Independent Variables: Child-Reported, Seven Years Old}

A range of other variables were included in the analysis taken from the child self-report questionnaire on the basis of the following criteria. First they should either relate to factors that have previously been identified as being associated with SWB with older children or where a plausible case can be made for a potential link. Second they should not themselves have an evaluative element which suggests a potential overlap with the SWB concept. This is a matter of judgement but it is clear to see for example that a question such as 'How much do you like school?' could be regarded as being close to a satisfaction question about the school domain which is part of the cognitive SWB concept and therefore can not really be regarded as an independent variable. Based on these criteria, nine variables were included in the analysis covering friendships (three 
variables); family relationships (two variables); academic motivation (one variable) and safety and bullying at school (three variables).

\subsubsection{Independent Variables: Family and Socio-Economic, Nine Months Old}

Information about the child's circumstances when they were nine months old is also included in the analysis to explore the potential influence of this on children's later SWB. The same variables as listed above at seven years old were used, plus a variable about maternal education and the main parent's age at the birth of the child. These are factors that have been associated with child outcomes in other studies (e.g. Kiernan and Mensah 2009).

\subsubsection{Control Variables}

All analysis controls for age (in days) of the child at the time that the Wave 4 data was gathered, gender, ethnicity and country of residence.

\subsection{Analysis}

The first part of the analysis process consisted of initial exploratory univariate and bivariate analysis to screen the data, collapse variables with sparse categories, and identify any other issues that needed to be taken into account in the multivariate analysis. There was some missing data for dependent and independent variables, although this was less than $2.5 \%$ for each of the variables utilised here. There were also some completely missing sets of data - just over 500 cases where parents did not answer any of the parent-reported variables about relationships with the child; and around 500 cases where the Wave 1 had not been collected. Imputation of missing data was considered when planning the analysis but was not utilised for several reasons. There is relatively little missing data for independent variables for cases included in the analysis. The main sources of missing data are on the dependent variables and some cases where Wave 1 data was not available. Imputation of dependent variables is not regarded as good practice (Von Hippel 2007) and imputation of complete missing waves of data in longitudinal analysis is of dubious value (Young and Johnson 2015). There was an additional complication in that some missing data for cases present at each wave, such as household income, had already been imputed by the survey team (Hansen 2014) and so should not be used for further imputations.

Following the above process, for each dependent variable, six logistic regression models were run. Model 0 contained only the control variables and provided a reference point for the added explanatory power of other models after taking account of control variables. All subsequent models also included these control variables. Model 1 used the family and socio-economic variables at seven years old. Model 2 used these variables plus the parent-reported variables on relationships with the child. Model 3 used the Model 1 variables plus the child-reported variables. Model 4 used the family and socio-economic variables from Wave 1 (when the child was nine months old). Finally, Model 5 included the family and socio-economic variables at both nine months and seven years old (multicollinearity was checked and was not a problem). The reason for including the Model 1 variables in Models 2 and 3 was to explore the 
explanatory power of parent-reported and child-reported variables after taking into account factors such as household income. The purpose of running Model 5 was to test whether the family and socio-economic variables at nine months old had any unique explanatory power once current circumstances were taken into account. This is a useful issue to explore because if there is little or no added value to this early childhood factors then this can strengthen the confidence in cross-sectional analysis results. On the other hand if the early childhood factors do explain additional variance in SWB then this emphasises the importance of taking a longitudinal perspective on variations in children's SWB.

Logistic regression models do have limitations in terms of being able to compare explanatory power of different models. The types of pseudo-R-squared statistics generated from these models are not suitable for this purpose (Mood 2010). Therefore linear regressions were also run for each of the models. This has the advantage that it is possible to generate R-squared statistics for model comparison purposes. Linear regression with binary dependent variables is commonly used by economists and it has been found to be a robust technique provided that the binary variable is not very unevenly split (Hellevik 2009). This was one of the factors that informed creating a roughly 75-25 split for the SDQ binary variable. Results of this additional analyses in terms of the contribution of independent variables were very close to those reported for the logistic regressions and there were no substantively important differences. The adjusted R-squared statistics for each linear model are reported at the end of each table, after the results of the logistic regression model.

All analysis was conducted using Stata 14. The MCS data set contains weights and information about the sample (clustering and stratification) which makes it possible to conduct analysis taking into account both the complex survey design and sample attrition. All analysis utilises this information using Stata's svyset option. All results are reported with $99 \%$ confidence intervals (in view of the large sample size).

\section{Results}

\subsection{Bivariate Results}

A bivariate analysis was conducted of the distribution of responses for each independent variable; and the percentage of children with low happiness, high sadness and high EBD scores respectively. Some noteworthy overall patterns were identified.

First, there were indications of some differences between patterns for positive and negative affect. For example, three of the four parent-reported variables about relationships with the child were more strongly associated with variations in happiness than sadness. On the other hand, sadness appeared to vary more with housing tenure (at either age measured) than happiness. Second, there were also indications of differences in patterns for affective SWB and EBD. There was generally more evidence of significant socio-economic differences for EBD than for SWB. For example, children living in lower income families tended to have higher EBDs but there was less evidence of a link between income and SWB, particularly for happiness. Similarly children who 
lived with a lone parent at seven years old had a higher EBD score but there was no clear difference in SWB between children living with one or two parents. Third, and further to the above point, some of the patterns of SWB were in the opposite direction to those for EBD. For example, children tended to be slightly more likely to have high happiness and low sadness, but greater likelihood of a high EBD score, in lower income households. Children with a younger main parent tended to have higher positive affect and lower negative affect but, on the other hand, higher EBD scores.

The next sections will describe the results of the series of linear regression models outlined earlier with positive affect and negative affect as dependent variables. For simplicity of language the findings are mostly discussed in terms of levels of happiness and sadness, although more precisely, because a binary variable is being used, these refer to the odds of high levels of happiness and sadness respectively. Later in this section a comparative overview is provided of results of models with the same sets of independent variables but with the EBD score as the dependent variable.

\subsection{Model 0: Control Variables Only}

In the logistic regression model with the four control variables only, girls had higher happiness than boys, but also higher sadness. There was no evidence of age variation (across this limited age span) for either SWB variable. There was very little evidence of substantive variations according to ethnicity. There was evidence of some variation between countries with children in England tending to have the lowest positive affect and highest negative affect. Explanatory power (adjusted R-squared) of these models using linear regression was low. Further details of this are summarized for all models in Table 6 towards the end of the section 3 .

\subsection{Model 1: Control plus Family and Socio-Economic Factors (Seven Years Old)}

Table 2 summarises logistic regressions for Model 1 adding family and socio-economic factors when the child was seven years old to Model 0 . The most striking thing here is that children living with siblings tended to have lower happiness than children not living with siblings. Apart from this pattern there was no evidence of family and socioeconomic factors at seven years old being significantly associated with children's happiness, but children who lived in a workless household had lower likelihood of sadness.

\subsection{Model 2: Model 1 plus Parent Report of Relationships with Child}

Table 3 shows statistics from logistic regression models including the four questions about parents' views of their relationship with the child. Statistics for variables already included in Model 1 are not shown for brevity and because patterns for these did not differ from what has already been described. There were some significant differences in relation to the parents' feelings of closeness and their enjoyment of being with the child. Where parents were more positive about these things children had significantly higher happiness, although the variations were not large. Additionally, parents getting irritated with the child was associated with lower happiness. There was less evidence of a link between these parent-reported variables and children's sadness with no 
Table 2 Logistic regressions of each dependent variable onto family and socio-economic factors at the age of seven years old (Model 1)

\begin{tabular}{|c|c|c|c|c|c|c|}
\hline & \multicolumn{2}{|l|}{ Happy } & \multicolumn{2}{|l|}{$\mathrm{Sad}$} & \multicolumn{2}{|c|}{ SDQ total difficulties } \\
\hline & O.R. & {$[99 \% \mathrm{CI}]$} & O.R. & {$[99 \% \mathrm{CI}]$} & O.R. & {$[99 \% \mathrm{CI}]$} \\
\hline One parent/carer & 0.90 & {$[0.75,1.08]$} & $1.19^{*}$ & {$[0.99,1.43]$} & 0.86 & {$[0.70,1.06]$} \\
\hline \multicolumn{7}{|c|}{ Equiv. income quintile (ref = Lowest) } \\
\hline Second quintile & 0.93 & {$[0.76,1.14]$} & 0.99 & {$[0.81,1.22]$} & 0.88 & {$[0.69,1.11]$} \\
\hline Third quintile & 0.93 & {$[0.73,1.17]$} & 1.10 & {$[0.86,1.40]$} & $0.68 * *$ & {$[0.54,0.86]$} \\
\hline Fourth quintile & 0.92 & {$[0.73,1.17]$} & 1.14 & {$[0.89,1.45]$} & $0.52 * *$ & {$[0.40,0.67]$} \\
\hline Highest quintile & 0.86 & {$[0.67,1.10]$} & 1.23 & {$[0.92,1.63]$} & $0.34 * *$ & {$[0.26,0.44]$} \\
\hline Owner-occupied housing & 1.01 & {$[0.86,1.18]$} & $1.15^{*}$ & {$[0.96,1.38]$} & $0.58 * *$ & {$[0.48,0.69]$} \\
\hline Parental worklessness & 1.09 & {$[0.87,1.36]$} & $0.71 * *$ & {$[0.56,0.91]$} & $1.36^{* *}$ & {$[1.09,1.69]$} \\
\hline \multicolumn{7}{|c|}{ Number of siblings (ref $=$ None) } \\
\hline One & $0.75 * *$ & {$[0.63,0.89]$} & 1.12 & {$[0.91,1.37]$} & $0.84^{*}$ & {$[0.67,1.05]$} \\
\hline Two & $0.72 * *$ & {$[0.59,0.88]$} & $1.21 *$ & {$[0.96,1.51]$} & 0.87 & {$[0.69,1.10]$} \\
\hline Three or more & $0.70^{* *}$ & {$[0.56,0.88]$} & 1.16 & {$[0.90,1.49]$} & $0.78^{*}$ & {$[0.61,1.01]$} \\
\hline Observations & 12,428 & & 12,428 & & 12,428 & \\
\hline Adjusted R-squared (lin. reg.) & $1.1 \%$ & & $1.5 \%$ & & $7.4 \%$ & \\
\hline
\end{tabular}

All models also included the following control variables: child's age in days at time of Wave 4 data collection, child's sex, child's ethnic group and country of residence at Wave 4

Key: $*=p<0.05 ; * *=p<0.01$

statistically significant coefficients at the $99 \%$ confidence level. Overall there is a some evidence here that more positive views of the parent about their relationship with the child are associated with higher child happiness but no firm evidence that they are associated with lower child sadness.

\subsection{Model 3: Model 1 plus Child-Reported Variables}

Turning to children's responses to other questions on the self-completion questionnaire there was much more evidence of significant and substantive links with children's SWB (Table 4). All of the child-reported variables showed a significant association with children's happiness. Children who had more friends, at least one good friend and liked playing with friends had higher positive affect. Children who got on well with siblings and had fun with their family at the weekend had higher positive affect. There were also links in the expected direction for trying one's best at school, feeling safe in the playground, being bullied and feeling left out by other children. There were also significant associations between most of the independent variables and sadness. However the variables regarding friendships did not contribute significantly to predicting sadness. On the other hand the size of the odds ratios for the variables regarding being bullied and being left out are notably large here. Thus there is evidence of different correlates and strengths of association of children's positive and negative affective SWB. 
Table 3 Logistic regressions of each dependent variable onto parent reports of relationship with child at the age of seven years old (Model 2)

\begin{tabular}{|c|c|c|c|c|c|c|}
\hline & \multicolumn{2}{|c|}{ Positive affect } & \multicolumn{2}{|c|}{ Negative affect } & \multicolumn{2}{|c|}{ SDQ total difficulties } \\
\hline & O.R. & {$[99 \% \mathrm{CI}]$} & O.R. & {$[99 \% \mathrm{CI}]$} & O.R. & {$[99 \% \mathrm{CI}]$} \\
\hline \multicolumn{7}{|l|}{ Close to child (ref = Extremely) } \\
\hline Very & $0.88^{* *}$ & {$[0.78,0.99]$} & 1.02 & {$[0.88,1.19]$} & 1.09 & {$[0.92,1.30]$} \\
\hline Not very / Fairly & 0.88 & {$[0.63,1.24]$} & 0.88 & {$[0.64,1.20]$} & $1.62 * *$ & {$[1.14,2.31]$} \\
\hline \multicolumn{7}{|c|}{ Enjoys time with child (ref = Always / Almost always) } \\
\hline Often & $0.86^{* *}$ & {$[0.75,0.97]$} & $1.14^{*}$ & {$[0.99,1.31]$} & $1.32 * *$ & {$[1.12,1.56]$} \\
\hline Never / Rarely/ Sometimes & 0.86 & {$[0.65,1.13]$} & 1.17 & {$[0.86,1.60]$} & $2.02 * *$ & {$[1.51,2.71]$} \\
\hline \multicolumn{7}{|c|}{ Expresses affect to child (ref = Always $/$ Almost always) } \\
\hline Often & 0.99 & {$[0.85,1.16]$} & 0.95 & {$[0.80,1.13]$} & 1.06 & {$[0.88,1.27]$} \\
\hline Never / Rarely/ Sometimes & 0.94 & {$[0.65,1.35]$} & 0.98 & {$[0.67,1.43]$} & 1.36 & {$[0.83,2.22]$} \\
\hline Gets irritated with child & $0.84 * *$ & {$[0.73,0.98]$} & 1.08 & {$[0.90,1.31]$} & $5.91 * *$ & {$[5.00,6.98]$} \\
\hline Observations & 12,153 & & 12,153 & & 12,153 & \\
\hline Adjusted R-squared (lin. reg.) & $1.5 \%$ & & $1.6 \%$ & & $20.7 \%$ & \\
\hline
\end{tabular}

All models also included the following control variables: child's age in days at time of Wave 4 data collection, child's sex, child's ethnic group and country of residence at Wave 4; and the family and socio-economic variables from Table 3

Key: $*=p<0.05 ; * *=p<0.01$

\subsection{Model 4: Controls plus Family and Socio-Economic Circumstances at Nine Months Old}

There were two significant associations between family and socio-economic circumstances at nine months old and children's happiness at seven years old. Children with highly-qualified parents in early childhood tended to have lower happiness than other children at seven years old; and children with siblings tended to have lower happiness than children without siblings. Family structure (lone or two parents), household income, parental work status, housing tenure and parental age at birth of child in early childhood made no significant contribution to explaining variations in children's happiness at seven years of age. The pattern linking highly-educated parents with lower child SWB was found for sadness also. Additionally, children whose parents were older when they were born tended to have higher sadness. For brevity a table is not shown for this model as the patterns are broadly the same as described in the next section.

\subsection{Model 5: Controls plus Family and Socio-Economic Circumstances at Nine Months and Seven Years Old}

The patterns noted in Model 4 regarding parental qualifications (for both positive and negative affect) and parental age (for negative affect) were both still present when family and socio-economic factors at seven years old were included in the model (Table 5). It is interesting to note that these patterns continue to suggest that children of 
Table 4 Logistic regressions of each dependent variable onto child-reported variables at the age of seven years old (Model 3)

\begin{tabular}{|c|c|c|c|c|c|c|}
\hline & \multicolumn{2}{|c|}{ Positive affect } & \multicolumn{2}{|c|}{ Negative affect } & \multicolumn{2}{|c|}{ SDQ total difficulties } \\
\hline & O.R.. & {$[99 \% \mathrm{CI}]$} & O.R. & {$[99 \% \mathrm{CI}]$} & O.R. & {$[99 \% \mathrm{CI}]$} \\
\hline \multicolumn{7}{|l|}{ Number of friends (ref = Lots) } \\
\hline Some & $0.63 * *$ & {$[0.55,0.73]$} & 1.12 & {$[0.95,1.32]$} & 1.09 & {$[0.92,1.29]$} \\
\hline Not many & $0.59 * *$ & {$[0.48,0.74]$} & 1.02 & {$[0.80,1.30]$} & $1.33 * *$ & {$[1.04,1.68]$} \\
\hline Has at least one best friend & 0.99 & {$[0.73,1.35]$} & 0.79 & {$[0.56,1.13]$} & 0.98 & {$[0.70,1.38]$} \\
\hline \multicolumn{7}{|c|}{ Likes playing with friends (ref=A lot) } \\
\hline A bit & $0.61 * *$ & {$[0.45,0.81]$} & 0.97 & {$[0.76,1.24]$} & 1.14 & {$[0.91,1.43]$} \\
\hline Not & $1.72 *$ & {$[0.95,3.14]$} & $0.52 *$ & {$[0.23,1.17]$} & 1.28 & {$[0.60,2.71]$} \\
\hline \multicolumn{7}{|c|}{ Gets along with siblings ( $\mathrm{ref}=$ All of the time) } \\
\hline Some of the time & $0.53 * *$ & {$[0.44,0.62]$} & $1.57 * *$ & {$[1.34,1.84]$} & $0.81 * *$ & {$[0.69,0.96]$} \\
\hline Never & $0.48 * *$ & {$[0.38,0.59]$} & 1.14 & {$[0.93,1.40]$} & 0.93 & {$[0.74,1.16]$} \\
\hline Does not have siblings & $0.73 *$ & {$[0.52,1.03]$} & 1.26 & {$[0.87,1.84]$} & 0.98 & {$[0.61,1.55]$} \\
\hline \multicolumn{7}{|c|}{ Has fun with family at weekend ( $\mathrm{ref}=$ All of the time) } \\
\hline Some of the time & $0.58 * *$ & {$[0.51,0.66]$} & $1.51 * *$ & {$[1.30,1.76]$} & 0.99 & {$[0.84,1.15]$} \\
\hline Never & $0.46^{* *}$ & {$[0.29,0.71]$} & 0.78 & {$[0.54,1.12]$} & 1.05 & {$[0.71,1.56]$} \\
\hline \multicolumn{7}{|c|}{ Tries best at school (ref $=$ All of the time) } \\
\hline Some of the time & $0.60 * *$ & {$[0.50,0.71]$} & 1.07 & {$[0.90,1.28]$} & $1.49 * *$ & {$[1.26,1.75]$} \\
\hline Never & 0.85 & {$[0.55,1.30]$} & $0.57 * *$ & {$[0.37,0.88]$} & $1.94 * *$ & {$[1.23,3.08]$} \\
\hline \multicolumn{7}{|c|}{ Feels safe in the playground ( $\mathrm{ref}=$ All of the time) } \\
\hline Some of the time & $0.60 * *$ & {$[0.53,0.68]$} & $1.34 * *$ & {$[1.15,1.56]$} & 1.06 & {$[0.92,1.22]$} \\
\hline Never & $0.64 * *$ & {$[0.46,0.90]$} & 0.98 & {$[0.69,1.38]$} & $1.52 * *$ & {$[1.12,2.08]$} \\
\hline \multicolumn{7}{|l|}{ Other children bully (ref = Never) } \\
\hline Some of the time & $0.86 * *$ & {$[0.75,0.98]$} & $1.58^{* *}$ & {$[1.37,1.81]$} & $1.49 * *$ & {$[1.25,1.77]$} \\
\hline All of the time & 1.01 & {$[0.79,1.29]$} & $1.46^{* *}$ & {$[1.13,1.88]$} & $2.03 * *$ & {$[1.58,2.60]$} \\
\hline \multicolumn{7}{|c|}{ Feels left out of things by other children (ref $=$ Never $)$} \\
\hline Some of the time & $0.55 * *$ & {$[0.48,0.63]$} & $2.34 * *$ & {$[2.05,2.67]$} & 0.90 & {$[0.77,1.06]$} \\
\hline All of the time & $0.75 * *$ & {$[0.57,0.97]$} & $1.37 * *$ & {$[1.02,1.82]$} & $1.45^{* *}$ & {$[1.10,1.93]$} \\
\hline Observations & 11,677 & & 11,677 & & 11,677 & \\
\hline Adjusted R-squared (lin. reg.) & $12.5 \%$ & & $9.4 \%$ & & $11.0 \%$ & \\
\hline
\end{tabular}

All models also included the following control variables: child's age in days at time of Wave 4 data collection, child's sex, child's ethnic group and country of residence at Wave 4; and the family and socio-economic variables from Table 3

Key: $*=p<0.05 ; * *=p<0.01$

older and more highly-educated parents tend to have the less positive than average affective SWB at the age of seven years old.

\subsection{Models for Emotional and Behavioural Difficulties}

The series of models described above were also run using the total difficulties score as a dependent variable and results are included in Tables 3, 4, 5, and 6. Overall there were 
Table 5 Logistic regressions of each dependent variable onto family and socio-economic factors at the age of nine months old (Model 5)

\begin{tabular}{|c|c|c|c|c|c|c|}
\hline & \multicolumn{2}{|c|}{ Positive affect } & \multicolumn{2}{|c|}{ Negative affect } & \multicolumn{2}{|c|}{ SDQ total difficulties } \\
\hline & O.R. & {$[99 \% \mathrm{CI}]$} & O.R. & {$[99 \% \mathrm{CI}]$} & O.R. & {$[99 \% \mathrm{CI}]$} \\
\hline One parent/carer & 0.99 & {$[0.78,1.25]$} & 0.85 & {$[0.65,1.11]$} & 0.89 & {$[0.68,1.16]$} \\
\hline \multicolumn{7}{|c|}{ Equiv. income quintile (ref = Lowest) } \\
\hline Second quintile & 0.96 & {$[0.76,1.21]$} & 1.01 & {$[0.79,1.29]$} & 0.89 & {$[0.69,1.16]$} \\
\hline Third quintile & 0.92 & {$[0.71,1.19]$} & 0.97 & {$[0.74,1.28]$} & $0.72 * *$ & {$[0.53,0.99]$} \\
\hline Fourth quintile & 0.96 & {$[0.73,1.26]$} & 0.97 & {$[0.76,1.26]$} & $0.70 * *$ & {$[0.50,0.98]$} \\
\hline Highest quintile & 0.91 & {$[0.65,1.28]$} & 1.13 & {$[0.85,1.49]$} & $0.60 * *$ & {$[0.41,0.86]$} \\
\hline Owner-occupied housing & 1.01 & {$[0.82,1.24]$} & 1.13 & {$[0.91,1.41]$} & $0.84^{*}$ & {$[0.68,1.05]$} \\
\hline Parental worklessness & 1.08 & {$[0.83,1.40]$} & 1.01 & {$[0.80,1.28]$} & 1.10 & {$[0.85,1.41]$} \\
\hline \multicolumn{7}{|l|}{ Number of siblings (ref= None) } \\
\hline One & $0.85^{* *}$ & {$[0.74,0.97]$} & 1.04 & {$[0.89,1.21]$} & 0.94 & {$[0.77,1.15]$} \\
\hline Two & $0.83^{*}$ & {$[0.67,1.03]$} & 0.96 & {$[0.76,1.22]$} & 0.92 & {$[0.70,1.21]$} \\
\hline Three or more & 0.93 & {$[0.65,1.33]$} & 0.94 & {$[0.64,1.39]$} & 0.85 & {$[0.58,1.24]$} \\
\hline \multicolumn{7}{|c|}{ Main parent qualification (ref = None) } \\
\hline NVQ Level 1 & 1.04 & {$[0.76,1.41]$} & 1.05 & {$[0.79,1.40]$} & $0.75^{* *}$ & {$[0.58,0.97]$} \\
\hline NVQ Level 2 & 0.87 & {$[0.68,1.12]$} & $1.25 *$ & {$[0.98,1.58]$} & $0.58 * *$ & {$[0.46,0.73]$} \\
\hline NVQ Level 3 & $0.77 * *$ & {$[0.60,1.00]$} & $1.36 * *$ & {$[1.03,1.80]$} & $0.55^{* *}$ & {$[0.41,0.73]$} \\
\hline NVQ Level 4 & $0.62 * *$ & {$[0.48,0.82]$} & $1.66^{* *}$ & {$[1.31,2.09]$} & $0.48 * *$ & {$[0.36,0.64]$} \\
\hline NVQ Level 5 & $0.51 * *$ & {$[0.35,0.76]$} & $2.74 * *$ & {$[1.84,4.08]$} & $0.58 * *$ & {$[0.35,0.97]$} \\
\hline Other & $0.71^{*}$ & {$[0.45,1.10]$} & 1.38 & {$[0.85,2.23]$} & 0.75 & {$[0.49,1.16]$} \\
\hline \multicolumn{7}{|l|}{ Main parent age $(\mathrm{ref}=$ Under 25$)$} \\
\hline 25 to 29 & 1.14 & {$[0.94,1.37]$} & $1.31 * *$ & {$[1.06,1.61]$} & $0.77 * *$ & {$[0.63,0.94]$} \\
\hline 30 to 34 & 1.08 & {$[0.89,1.31]$} & $1.33 * *$ & {$[1.06,1.67]$} & $0.67 * *$ & {$[0.53,0.83]$} \\
\hline 35 and over & 1.05 & {$[0.82,1.33]$} & $1.26^{*}$ & {$[0.97,1.65]$} & $0.68 * *$ & {$[0.53,0.87]$} \\
\hline Observations & 11,969 & & 11,969 & & 11,969 & \\
\hline Adjusted R-squared (lin. reg.) & $1.8 \%$ & & $2.8 \%$ & & $9.5 \%$ & \\
\hline
\end{tabular}

All models also included the following control variables: child's age in days at time of Wave 4 data collection, child's sex, child's ethnic group and country of residence at Wave 4; and the family and socio-economic variables from Table 3

Key: $*=p<0.05 ; * *=p<0.01$

very different patterns here. There was much more evidence of an income gradient in EBD than SWB with children in poorer families at the age of seven tending to have higher EBD, as did children living in rented accommodation at that age (Model 1). There was also evidence (Model 5) that early circumstances had some unique predictive power even when taking circumstances at seven years old into account. Children living with a younger main parent, with lower income, not in owned housing and with more poorly qualified parents at the age of nine months old tended to have greater EBD at seven years old. 
Table 6 Summary of explanatory power of different models (based on linear regressions with binary dependent variables

\begin{tabular}{|c|c|c|c|c|c|c|}
\hline & \multicolumn{2}{|c|}{ Positive affect } & \multicolumn{2}{|c|}{ Negative affect } & \multicolumn{2}{|c|}{ SDQ total difficulties } \\
\hline & $\mathrm{R}^{2}$ & $\Delta \mathrm{R}^{2}$ & $\mathrm{R}^{2}$ & $\Delta \mathrm{R}^{2}$ & $\mathrm{R}^{2}$ & $\Delta \mathrm{R}^{2}$ \\
\hline Model 0 (Controls) & $0.8 \%$ & na & $0.8 \%$ & na & $1.3 \%$ & na \\
\hline Model 1 (Model $0+$ Family/SES at 7 years old) & $1.1 \%$ & $+0.3 \%$ & $1.5 \%$ & $+0.7 \%$ & $7.4 \%$ & $+6.1 \%$ \\
\hline Model 2 (Model 1 + Parent-reported variables) & $1.5 \%$ & $+0.4 \%$ & $1.6 \%$ & $+0.2 \%$ & $20.7 \%$ & $+13.3 \%$ \\
\hline Model 3 (Model 1 + Child-reported variables) & $12.5 \%$ & $+11.4 \%$ & $9.4 \%$ & $+7.9 \%$ & $11.0 \%$ & $+3.6 \%$ \\
\hline Model 4 (Model $0+$ Family/SES at 9 months old) & $0.9 \%$ & $+0.1 \%$ & $2.5 \%$ & $+1.7 \%$ & $9.0 \%$ & $+7.7 \%$ \\
\hline Model 5 (Model $1+$ Family/SES at 9 months old) & $1.8 \%$ & $+1.0 \%$ & $2.7 \%$ & $+1.9 \%$ & $9.5 \%$ & $+8.2 \%$ \\
\hline
\end{tabular}

$\Delta \mathrm{R}^{2}$ shows the change in $\mathrm{R}^{2}$ compared to the model stated in brackets

For the parent-reported variables about relationships with the child (Model 3), where parents reported less closeness, less enjoyment of being with the child and more irritation with the child, children tended to have higher EBD. Of course in this case it is reasonable to think that there may be bidirectional influences at play here. There was a little less evidence of significant associations between the childreported variables and EBD than there is for the two affective SWB variables, although most of the variables did contribute significantly to predicting the likelihood of high EBDs.

\subsection{Comparing the Explanatory Power of Different Models}

Most of the models discussed above had at least some independent variables that made a unique significant contribution to explaining some of the variation in the dependent variable. However, with a sample of this size it is quite common for this to be the case for variables that do not have a substantive effect size in terms of the differences in the dependent variable that they relate to. So it is also important and useful to look at the explanatory power of the models. Table 6 summarizes the explanatory power of each model for each binary dependent variable using linear regression as discussed earlier.

For positive affect and negative affect the only model that explained more than $3 \%$ of the variation in the SWB variable was Model 3 which included the childreported variables. In total, after taking account of control and family and socioeconomic variables, the child-reported variables added around $11 \%$ and $8 \%$ explanatory power in terms of predicting happiness and sadness respectively. These are reasonably large values for SWB research. Comparisons with the models for the EBD variables illustrate some important differences. The models with family and socio-economic variables explain much more of the variation in EBD than SWB. For example, Model 5 including these independent variables at nine months old and seven years old explained over $9 \%$ of the variation in EBD compared to less than $3 \%$ of the variation in positive affect and negative affect. The other striking difference is the large explanatory power of the parent-reported 
variables for EBD. Model 3 with control variables, family and socio-economic variables at the age of seven years old and parent-reported views of child relationships explained $20 \%$ of the variation in EBD compared to less than $2 \%$ of the variation in positive affect and negative affect. As noted earlier, this finding could highlight that where children have EBD, parents have less positive views on their relationship with the child, as well as that the quality of the relationship influences EBD. Both explanations are plausible and the mechanisms at play may be quite complex. The comparison of explanatory powers indicates that the same dynamic does not seem to exist between parents' views of their relationship with the child and the child's affective SWB, as the explanatory power here is quite weak. It should also be acknowledged that the EBD measure is as reported (and therefore perceived) by parents. It would be useful to extend this analysis to include measures of EBD reported by other people - such as teachers.

\section{Discussion}

The analysis presented here extends existing knowledge about children's SWB in three ways. It contributes to the relatively limited body of evidence relating to the SWB of children under the age of ten years old; it also incorporates a longitudinal element which has been relatively lacking in much research in this field; and it provides a point of comparison with findings for a different type of indicator of children's well-being - their emotional and behavioural difficulties. The analysis set out to explore which factors in children's lives at the age of seven years old predicted their affective SWB; whether factors earlier in childhood could predict children's SWB at seven years old; and the differences and similarities between findings for SWB and EBD. In broad terms, the results indicate that family, socioeconomic and parent-reported factors explain relatively little of the variation in children's affective SWB at the age of seven years old but that other information reported by the child about their views of their relationships with friends and family and issues of safety, bullying and social exclusion at school play a more important role. These patterns differ in a number of ways when considering variations in children's EBD.

The fact that family and socio-economic factors explain little of the variation in children's affective SWB is not unexpected. Previous research with older children in the UK has reported similar findings, particularly when using indicators like family structure and household income, although measures of child-centred material deprivation explain more of the variation in SWB (Main and Bradshaw 2012; Main 2014). Additionally, from a conceptual point of view, affective SWB might be expected to be less influenced by these kind of long-term structural factors than cognitive SWB.

The finding about the lack of substantial explanatory power of parent reports of the quality of their relationships with their child and the child's SWB is, on the surface of it, more surprising. Previous UK research has highlighted the 
quality of family relationships (at least as reported by children) as an important factor linked to variation in their SWB (Rees et al. 2010). It might be argued that affective SWB might also be less influenced by this factor than cognitive SWB but Rees and Bradshaw (2016) did not find much evidence of this hypothesis with children aged 11 years old. However other research has also found that parent-reported views on their relationships with children of 11 years old are not the strongly related with children's SWB (Rees and Bradshaw 2016). As the quality of children's relationships has emerged as such an important topic in research on their SWB this is a topic that would benefit from further exploration. Ideally research would make use of similar indicators of quality of family relationships from both a child and parent's perspective in a paired sample with the aim of understanding the extent of similarity and difference between them and with SWB (perhaps of parents and children).

The link between child-reported factors and children's SWB is less surprising. Previous UK research (e.g. Goswami 2012; Rees and Bradshaw 2016) has consistently found that factors in children's lives reported by children themselves such as bullying, peer relationships and quality of family relationships are some of the strongest predictors of variations in children's SWB. The analysis presented in this paper extends that finding to younger children. It also suggests that the variations in SWB reported by children aged seven years old are meaningful in terms of how they experience specific aspects of their lives.

The finding of the lack of predictive power of early childhood circumstances in terms of children's SWB at the age of seven also adds to and supports the limited evidence on this particular issue (Parkes et al. 2016). Rees (2017) found a similar pattern in relation to children's cognitive SWB at the age of 11 years old. The fact that variations in SWB at an earlier age, closer to early childhood circumstances, show the same of lack association strengthens the idea that children's SWB is much more determined by current than historical factors.

The results suggest that the relationship between some family factors and children's SWB at the age of seven years old runs in a direction that is unexpected, based on previous research on the link between these factors and other measures of children's well-being. Children had higher positive and lower negative affect if they lived with a main parent who had fewer educational qualifications. This runs in the opposite direction to the association between parental qualifications and children's cognitive development (Kiernan and Mensah 2009) and also between parental qualifications and children's emotional and behavioural difficulties as shown in Table 5. The pattern shown in Table 5 that children living with an older parent tended to have higher levels of sadness is also unexpected. The size of these effects is quite small but they are nevertheless an important indication that the factors associated with children's SWB are not necessarily the same as those associated with other commonly measured child outcomes. The reasons for these differences require more exploration, but other findings have emerged that challenge accepted ideas of the extent and direction of socio-economic determinants of children's wellbeing. For example, Powdthavee and Vernoit (2013) found that parental 
unemployment was associated with slightly elevated life satisfaction among children aged 11 years old although the direction of effect was reversed among older teenagers. Knies (2017) found a positive association between household income and children's life satisfaction in the UK only from the age of 13 years old upwards. It is therefore possible that socio-economic factors affect children's SWB in different ways, and perhaps even in opposite directions, at different ages. This is an important area for further research.

The comparatively different pattern of findings when using the same sets of independent variables to predict emotional and behavioural difficulties at the age of seven years old provides further evidence (Patalay and Fitzsimons 2016; Rees 2017) to support the distinction between measures of positive well-being and measures of children's difficulties. This analysis indicates that the early childhood circumstances being considered have more predictive power in terms of emotional and behavioural difficulties than affective subjective well-being.

In terms of practical implications, overall the findings suggest that the reasons why some children aged seven years old feel happier or sadder than others is best understood in terms of the current conditions of their lives, rather than the effect of events earlier in childhood. This means that initiatives to address current conditions associated with lower SWB could potentially have benefits in terms of improving children's quality of life at this age. This leaves the question of where efforts might most effectively targeted. Socio-economic conditions do not seem to be a major determinant of children's affective SWB. The situation with parent-child relationships is less clear. Parent's assessments of these relationships did not seem closely associated with how children felt about their lives. However, given other research which has found that family relationships (as viewed by children) are important correlates of SWB, it would seem unlikely that this was not also an important factor with this age group. Finally, peer relationships are clearly an important part of the overall picture of variations in children's SWB and, as with older children, experiences of being bullied emerge as important explanatory factors. Here also directions of causality are unclear, but it is plausible that initiatives to tackle bullying could substantially improve children's SWB, particularly in terms of reducing high negative affect. Anti-bullying strategies could also have longer-term benefits as it is now established that the negative impact of childhood bullying extends far into adulthood (Ttofi et al. 2011; Takizawa et al. 2014; Wolke and Lereya 2015).

Some limitations of the paper, related to the available data in the data set, should be noted. First, the indicators of SWB and the use of binary variables substantially limits the scope for the analysis and means that the findings presented here are best seen as highlighting issues that could be researched in more detail. Future research might develop better multi-item measures of children's positive and negative affect; and also explore whether it is possible to develop valid and reliable measures of children's cognitive SWB for this age group. Second, the available independent variables are limited in some important ways. For example there is no data on children's views of family relationships which is a major gap in the analysis presented. Future primary research could address this issue. Nevertheless the large and representative sample size; 
the ability to link data from children with other family data and also longitudinally are strengths.

Open Access This article is distributed under the terms of the Creative Commons Attribution 4.0 International License (http://creativecommons.org/licenses/by/4.0/), which permits unrestricted use, distribution, and reproduction in any medium, provided you give appropriate credit to the original author(s) and the source, provide a link to the Creative Commons license, and indicate if changes were made.

\section{References}

Abdallah, S., Main, G., Pople, L., \& Rees, G. (2014). Ways to well-being: Exploring the links between children's activities and their subjective well-being. London: The Children's Society.

Andrews, F., \& Withey, S. (1976). Social indicators of well-being: Americans' perceptions of life quality. New York: Plenum Press.

Barrett, L. F. \& Russell, J. A. (1998) Independence and bipolarity in the structure of current affect. Journal of Personality and Social Psychology, 74 (4):967-984

Bergsma, A., Ten Have, M., Veenhoven, R., \& Graaf, R. d. (2011). Most people with mental disorders are happy: a 3-year follow-up in the Dutch general population. The Journal of Positive Psychology, 6(4), 253-259. https://doi.org/10.1080/17439760.2011.577086.

Dickerson, A., \& Popli, G. K. (2015). The many dimensions of child poverty: Evidence from the UK millennium cohort study (working paper). Sheffield: University of Sheffield.

Diener, E. (1984). Subjective well-being. Psychological Bulletin, 95(3), 542-575. https://doi.org/10.1037 /0033-2909.95.3.542.

Flouri, E., Midouhas, E., \& Ruddy, A. (2016). Socio-economic status and family structure differences in early trajectories of child adjustment: individual and neighbourhood effects. Health \& Place, 37, 8-15. https://doi.org/10.1016/j.healthplace.2015.11.005.

Goodman, R. (1997). The strengths and difficulties questionnaire: a research note. Journal of Child Psychology and Psychiatry, 38(5), 581-586. https://doi.org/10.1111/j.1469-7610.1997.tb01545.x.

Goodman, A., \& Goodman, R. (2012). Strengths and difficulties questionnaire scores and mental health in looked after children. The British Journal of Psychiatry, 200(5), 426-427. https://doi.org/10.1192/bjp. bp.111.104380.

Goodman, R., Meltzer, H., \& Bailey, V. (1998). The strengths and difficulties questionnaire: a pilot study on the validity of the self-report version. European Child \& Adolescent Psychiatry, 7(3), 125-130.

Goswami, H. (2012). Social relationships and children's subjective well-being. Social Indicators Research, 107(3), 575-588. https://doi.org/10.1007/s11205-011-9864-z.

Goswami, H. (2014). Children's subjective well-being: socio-demographic characteristics and personality. Child Indicators Research, 7, 119-140. https://doi.org/10.1007/s12187-013-9205-7.

Hansen, K. (ed.) (2014). Millennium cohort study: A guide to the datasets (eighth edition): First, second, third, fourth and fifth surveys. London: Centre for Longitudinal Studies.

Hellevik, O. (2009). Linear versus logistic regression when the dependent variable is a dichotomy. Quality and Quantity, 43(1), 59-74. https://doi.org/10.1007/s11135-007-9077-3.

Huebner, E. S., \& Dew, T. (1996). The interrelationships of positive affect, negative affect, and life satisfaction in an adolescent sample. Social Indicators Research, 38(2), 129-137. https://doi.org/10.1007 /BF00300455.

Kiernan, K. E., \& Mensah, F. K. (2009). Poverty, maternal depression, family status and Children's cognitive and Behavioural development in early childhood: a longitudinal study. Journal of Social Policy, 38(04), 569. https://doi.org/10.1017/S0047279409003250.

Knies, G. (2017). Income effects on children's life satisfaction: Longitudinal evidence for England (ISER working paper 2017-02). Colchester: Institute for Social and Economic Research, University of Essex.

Main, G. (2014). Child poverty and children's subjective well-being. Child Indicators Research, 7(3), 451472. https://doi.org/10.1007/s12187-014-9237-7.

Main, G., \& Bradshaw, J. (2012). A child material deprivation index. Child Indicators Research, 5(3), 503521. https://doi.org/10.1007/s12187-012-9145-7.

Mood, C. (2010). Logistic regression: why we cannot do what we think we can do, and what we can do about it. European Sociological Review, 26(1), 67-82. https://doi.org/10.1093/esr/jcp006. 
Parkes, A., Sweeting, H., \& Wight, D. (2016). What shapes 7-year-olds' subjective well-being? Prospective analysis of early childhood and parenting using the growing up in Scotland study. Social Psychiatry and Psychiatric Epidemiology, 51(10), 1417-1428. https://doi.org/10.1007/s00127-016-1246-z.

Patalay, P., \& Fitzsimons, E. (2016). Correlates of mental illness and wellbeing in children: are they the same? Results from the UK millennium cohort study. Journal of the American Academy of Child \& Adolescent Psychiatry, 55(9), 771-783. https://doi.org/10.1016/j.jaac.2016.05.019.

Powdthavee, N., \& Vernoit, J. (2013). Parental unemployment and children's happiness: a longitudinal study of young people's well-being in unemployed households. Labour Economics, 24, 253-263. https://doi. org/10.1016/j.labeco.2013.09.008.

Rees, G., Bradshaw, J., Goswami, H., \& Keung, A. (2010). Understanding children's well-being: A national survey of young people's well-being. London: The Children's Society.

Rees, G., \& Main, G. (2015). Children's views on their lives and well-being in 15 countries: A report on the Children's Worlds survey, 2013-14. York: Children's Worlds Project (ISCWeB).

Rees, G., \& Bradshaw, J. (2016). Exploring low subjective well-being among children aged 11 in the UK: an analysis using data reported by parents and by children. Child Indicators Research. https://doi. org/10.1007/s12187-016-9421-z.

Rees, G., Andresen, S., \& Bradshaw, J. (2016). Children's views on their lives and well-being in 16 countries: A report on the Children's Worlds survey of children aged eight years old, 2013-15. York: Children's Worlds Project (ISCWeB).

Rees, G. (2017). The association of childhood factors with children's subjective well-being and emotional and behavioural difficulties at 11 years old. Child Indicators Research. https://doi.org/10.1007/s12187-0179479-2.

Robson, K. (2010). Changes in family structure and the well-being of British children: evidence from a fifteenyear panel study. Child Indicators Research, 3(1), 65-83. https://doi.org/10.1007/s12187-009-9057-3.

Sabates, R., \& Dex, S. (2015). The impact of multiple risk factors on young children's cognitive and behavioural development. Children \& Society, 29(2), 95-108. https://doi.org/10.1111/chso.12024.

Takizawa, R., Maughan, B., \& Arseneault, L. (2014). Adult health outcomes of childhood bullying victimization: evidence from a five-decade longitudinal British birth cohort. American Journal of Psychiatry, 171(7), 777-784. https://doi.org/10.1176/appi.ajp.2014.13101401.

Ttofi, M. M., Farrington, D. P., Lösel, F., \& Loeber, R. (2011). Do the victims of school bullies tend to become depressed later in life? A systematic review and meta-analysis of longitudinal studies. Journal of Aggression, Conflict and Peace Research, 3(2), 63-73. https://doi.org/10.1108/17596591111132873.

Von Hippel, P. T. (2007). Regression with missing Ys: an improved strategy for analyzing multiply imputed data. Sociological Methodology, 37(1), 83-117. https://doi.org/10.1111/j.1467-9531.2007.00180.x.

Wolke, D., \& Lereya, S. T. (2015). Long-term effects of bullying. Archives of Disease in Childhood, 100(9), 879-885. https://doi.org/10.1136/archdischild-2014-306667.

Young, R., \& Johnson, D. R. (2015). Handling missing values in longitudinal panel data with multiple imputation. Journal of Marriage and Family, 77(1), 277-294. https://doi.org/10.1111/jomf.12144. 